\title{
MUDANÇAS CAMBIAIS E O EFEITO DOS FATORES DE CRESCIMENTO DAS RECEITAS DE EXPORTAÇÕES BRASILEIRAS DE SOJA ${ }^{1}{ }^{2}$
}

\author{
Sonia Sueli Serafim de Souza ${ }^{3}$ \\ Janice Alves Lamera ${ }^{4}$ \\ Sandra Cristina de Moura Bonjour ${ }^{5}$ \\ Adriano Marcos Rodrigues Figueiredo ${ }^{6}$
}

Resumo - Neste artigo são analisados os efeitos da taxa de câmbio, da quantidade exportada e do preço internacional da soja sobre a receita de exportação dessa commodity, no período de 1994 a 2005. A análise foi feita através do método shift-share, que permite verificar o efeito isolado de cada uma das variáveis estudadas sobre a referida receita. Os resultados apontaram que, mesmo diante de uma situação adversa do câmbio e do preço internacional, a quantidade exportada manteve-se crescente por quase todo o período. Pode-se observar ainda que as duas formas de política cambial adotadas pelo governo brasileiro desde o início do Plano Real, em 1994, foram visivelmente decisivas para o crescimento das receitas e da quantidade exportada de soja em grão.

Palavras-chave: taxa de câmbio, receita de exportação, soja.

\section{Introdução}

Um dos mais significativos aspectos da transformação que a economia brasileira vem experimentando é o crescimento da importância do agronegócio nacional no cenário mundial. Hoje, assim como se reconhece que a China caminha para dominar o setor industrial e a Índia, o segmento de serviços associado à tecnologia da informação, existe uma disseminada

\footnotetext{
Recebido em 27/09/2006. Aceito em 09/01/2007.

Os autores agradecem aos revisores anônimos, pelas sugestões, e à FAPEMAT e CNPq, pelo auxílio financeiro. Mestranda em Agronegócio e Desenvolvimento Regional pela UFMT. E-mail: sonia_sueli@yahoo.com.br. 4 Mestranda em Agronegócio e Desenvolvimento Regional pela UFMT. E-mail: janice_alves@yahoo.com.br. 5 Professora Adjunta do Departamento de Economia da UFMT. E-mail: sbonjour@ufmt.br.

6 Professor Adjunto do Departamento de Economia da UFMT. E-mail: adriano@ufmt.br.
} 
percepção de que o Brasil é um importante agente em boa parte dos ramos do setor agroalimentar e agroenergético (Conjuntura Econômica, 2006).

Diante de um quadro em que a receita brasileira com as exportações de soja em grão declinou nos anos 90 e apresentou significativo crescimento nos anos seguintes, pretendeu-se analisar os fatores que têm afetado as receitas brasileiras de soja em grão no período analisado. Portanto, o presente trabalho teve por objetivo geral identificar os fatores que têm afetado as receitas de exportação de soja em grão e, mais especificamente, quantificar as variações nas receitas dos produtores provenientes da taxa de câmbio, do preço doméstico e da quantidade exportada.

Para decompor os efeitos do câmbio, do preço e da quantidade na receita de exportação, foi utilizado o método diferencial-estrutural, também designado shift-share, detalhado na seção 2. Segundo Shikida e Alves (2001), o estudo pioneiro com o modelo foi elaborado por Curtis (1972) para analisar o desempenho das variáveis renda e emprego, decompostas em três efeitos - crescimento nacional, composição das atividades econômicas e diferenciação regional das atividades econômicas — para o período de 1960 a 1969.

Dentre os trabalhos analisados que utilizaram o modelo shift-share estão os de Igreja et al. (2005), Silva (1999), Santos e Silva (2001), Silva et al. (1999), Romão et al. (1989), Shikida e Alves (2001), Souza et al. (2002), Canuto e Xavier (1999) e Reis e Campos (1998). Aqueles que mais especificamente serviram de base para a elaboração deste trabalho foram os de Filgueiras et al. (2003) e Igreja et al. (2005). Segundo Romão et al. (1989), o método tem inúmeras possibilidades de aplicação, especialmente em economia regional, e, devido a essa vantagem, tem resistido ao tempo e à crítica. 
Sonia Sueli Serafim de Souza, Janice Alves Lamera,

Sandra Cristina de Moura Bonjour \& Adriano Marcos Rodrigues Figueiredo

Dessa forma, contribui-se com a literatura em economia agrícola ao abordar a análise das variações nas receitas de exportações de soja considerando o detalhamento de seus componentes.

A seguir é feito um retrospecto da exportação de soja no período recente. $\mathrm{Na}$ seção 2, têm-se uma descrição do modelo analítico diferencialestrutural e as fontes dos dados. Na terceira seção estão os resultados e a discussão, seguida da seção de conclusões.

\subsection{A exportação de soja no periodo recente}

Segundo o Centro de Estudos Avançados em Economia Aplicada CEPEA (2006) e a Confederação da Agricultura e Pecuária do Brasil CNA (2006), os dados consolidados de 2005 para o agronegócio brasileiro mostram que, no acumulado do ano anterior, o PIB da agricultura nacional acusou retração de $15,46 \%$, com redução de $0,10 \%$ em dezembro, o que representou recuo de R $\$ 15,58$ bilhões em 2005, com um PIB de R $\$$ 85,20 bilhões a preços de 2005 , ante os $\mathrm{R} \$ 100,78$ bilhões de 2004 . Foram dois anos consecutivos de perdas de renda no campo, as quais tiveram início em outubro de 2003.

Em igual período de 2004, o resultado da agricultura foi de retração de 1,74\%. Em 2005 a lavoura apresentou redução de $0,72 \%$ na produção física e queda dos preços médios reais em torno de $14,85 \%$, combinação que reduziu drasticamente a renda do agricultor.

Até a década de 1980, o cultivo da soja se concentrava apenas nos Estados da região Sul do Brasil; após esse período, com o surgimento de cultivares adaptadas ao tipo de solo e ao clima das outras regiões brasileiras, o cultivo da soja atingiu os Estados de Mato Grosso, Mato Grosso do Sul e Goiás, no Centro-Oeste, e Bahia, Maranhão e Piauí, no Nordeste. 
Após a década de 1980, o Centro-Oeste tornou-se expressivo no cultivo dessa oleaginosa, em virtude do baixo valor das terras nessa região em relação às da região Sul do País. Essa cultura cresceu significativamente em todo o País, através da incorporação de novas terras ao cultivo, de áreas inexploradas e também da substituição de outras culturas.

Na safra 2004/05, a região Centro-Oeste produziu 28,594 milhões de toneladas de soja, enquanto a produção nacional foi de 51,451 milhões de toneladas, e a projeção para a safra 2005/06 do Centro-Oeste era de 29,058 milhões de toneladas, com variação de 1,6\% em relação à safra anterior. A produção total da região Sul do Brasil na safra 2004/05 foi de 12,793 milhões de toneladas, e para a safra 2005/06 havia uma expectativa de 19,562 milhões de toneladas, com incremento de 52,9\% em relação à safra 2004/05, conforme Figura 1 (IBGE/SIDRA, 1994 a 2005).

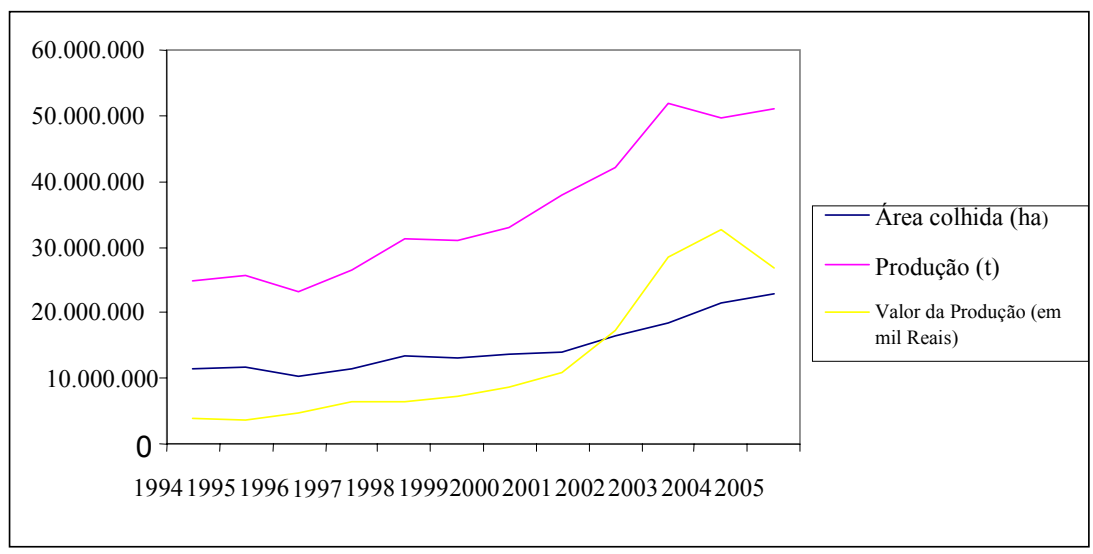

Figura 1 - Área colhida, produção e valor da produção de soja no Brasil - 1994 a 2005.

Fonte: IBGE - SIDRA/CONAB (Companhia Nacional de Abastecimento). Pesquisa Agrícola Municipal - PAM.

O complexo soja é o primeiro no ranking das exportações do agronegócio brasileiro. Com referência ao preço da soja no mercado internacional, 
Sonia Sueli Serafim de Souza, Janice Alves Lamera,

Sandra Cristina de Moura Bonjour \& Adriano Marcos Rodrigues Figueiredo

ele esteve instável ao longo da década de 1990 e, no início do período de 2000, caiu para um nível abaixo da média. Na safra 2003/04 houve forte recuperação do preço internacional do grão, permanecendo elevado até meados de 2004, quando caiu para um nível inferior ao da média histórica, assim permanecendo até o período atual.

De acordo com Brandão et al. (2005), foi a quebra das safras americanas de soja em 2002 e 2003 que incentivou o aumento da produção da oleaginosa no Brasil e na Argentina, após 1999, ou melhor, nas safras 2000/2001, 2001/2002 e, sobretudo, no ano agrícola 2002/2003, no qual os dois países colheram 88 milhões de toneladas, $20 \%$ a mais que na safra anterior. Se as quebras sucessivas da safra americana não tivessem ocorrido no ano de 2001, o aumento da produção mundial de soja teria sido de $8,5 \%$ em 2002 e de $0,9 \%$ em 2003, e não de 4\%, como foi, além de haver preços internacionais favoráveis, influenciados pela demanda chinesa e taxa de câmbio.

Conforme a Figura 2, houve mudanças significativas nos determinantes das exportações de soja brasileira na década de 1990, em razão da abertura da economia brasileira e da implantação de programas de estabilização econômica. 


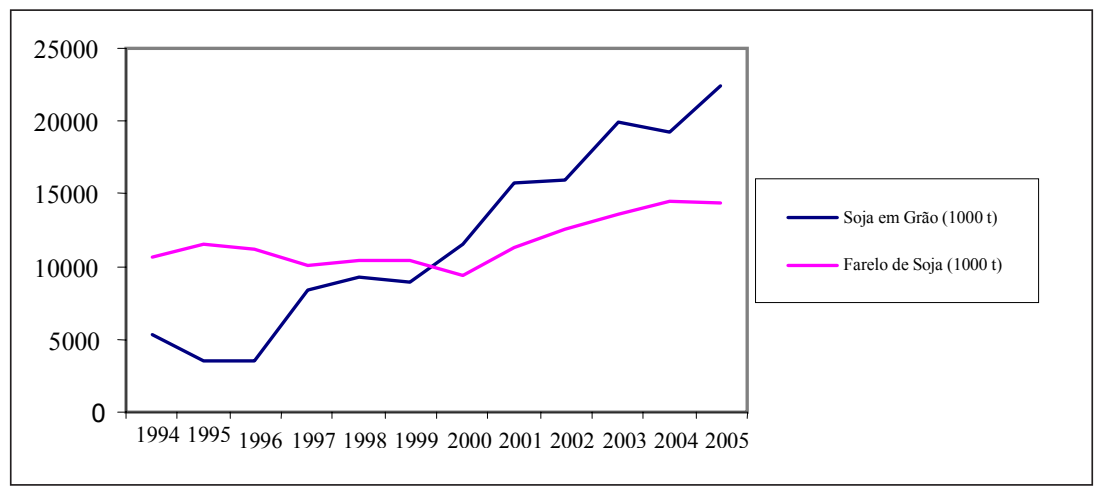

Figura 2 - Volume das exportações brasileiras de soja em grão e farelo de soja - 1994 a 2005.

Fonte: MDIC, 2006.

Com relação às exportações de soja em grão, estas se reduziram significativamente no ano de 1995, quando foram exportadas apenas 3.493 mil toneladas, diante das 5.367 mil toneladas da safra anterior, e isso se deveu a reflexos da valorização cambial promovida pelo Plano Real.

Após esse período, voltaram a crescer e, em 2000, ultrapassaram as exportações de farelo de soja. No ano de 2005 foram exportadas 22.435 mil toneladas de soja em grão e 14.422 mil toneladas de farelo de soja.

\section{Metodologia}

\subsection{Modelo analítico}

A análise das variações na receita de exportação brasileira de soja em grão foi feita pelo método diferencial-estrutural, também designado shiftshare. Este método permite decompor o efeito de algumas variáveis sobre a receita das exportações da referida commodity. 
Sonia Sueli Serafim de Souza, Janice Alves Lamera,

Sandra Cristina de Moura Bonjour \& Adriano Marcos Rodrigues Figueiredo

Silva e Carvalho (1995 apud Reis; Campos, 1998) afirmam que esta metodologia permite mensurar os efeitos da variação cambial sobre os preços entre diferentes momentos no tempo. Com isso, é possível verificar o efeito das diferentes políticas cambiais sobre um mercado específico, como o da soja. Os efeitos são captados pelas variações de seus componentes no tempo, e não se considera a interação entre as fontes; por isso, quando se analisa um dos efeitos, o outro é dado como constante.

Este estudo se diferencia dos anteriormente citados por tratar da receita de exportação de soja em grão no período de 1994 a 2005 e pelo fato de os efeitos aqui estudados serem decompostos em efeito preço, efeito câmbio e efeito quantidade, os quais serão mais bem detalhados adiante.

A receita da exportação da soja é definida da seguinte forma:

$$
R=Q \cdot P_{R \$}
$$

em que R é a receita em real decorrente da exportação da soja; Q, a quantidade de soja exportada em tonelada; $\mathrm{e}_{\mathrm{RS}}$, o preço em reais recebido pelo exportador brasileiro.

Como o preço da soja é definido no mercado internacional, a conversão para preço em reais é obtida pelo produto da taxa de câmbio real pelo preço em dólares:

$\mathrm{P}_{\mathrm{RS}}=\lambda \cdot \mathrm{P}_{\mathrm{USS}}$

em que $\mathrm{P}_{\text {USs }}$ é o preço em dólar recebido pelo exportador brasileiro e $\lambda$, a taxa de câmbio real (R\$/US\$).

Substituindo (2) em (1), tem-se que a receita da exportação de soja é resultante da quantidade exportada, da taxa de câmbio e do preço internacional da soja, ou seja: 
$\mathrm{R}=\mathrm{Q} \cdot\left(\lambda \cdot \mathrm{P}_{\mathrm{USS}}\right)$

A análise será anual, ou seja, será obtida a taxa anual de crescimento ou decrescimento da receita das exportações de soja, resultante da variação ocorrida entre o ano analisado ( $\mathrm{t}$ ) e o ano anterior (0). As expressões (4) e (5) apresentam a variação da receita de exportação de soja em reais, respectivamente, para o período inicial " 0 " e o período final " $t$ ":

$\mathrm{R}_{0}=\mathrm{Q}_{0} \cdot\left(\mathrm{P}_{\mathrm{Uss0}} \cdot \lambda_{0}\right)$

$\mathrm{R}_{\mathrm{t}}=\mathrm{Q}_{\mathrm{t}}\left(\mathrm{P}_{\mathrm{US \$ t}} \cdot \lambda_{\mathrm{t}}\right)$

Na expressão (6), tem-se o "efeito preço", que indica a variação na receita em reais ocorrida devido à variação no preço em dólares, e na expressão (7), o "efeito câmbio", que capta o efeito da variação da taxa de câmbio sobre a receita. Observe que, ao calcular cada um dos efeitos, os demais serão sempre considerados constantes:

$$
\begin{aligned}
& R_{t}^{P}=Q_{0}\left(\mathrm{P}_{\mathrm{USSt}} \cdot \lambda_{0}\right) \\
& R_{t}^{\lambda}=Q_{0}\left(\mathrm{P}_{\mathrm{USSt}} \cdot \lambda_{\mathrm{t}}\right)
\end{aligned}
$$

O efeito total ou a variação total na receita das exportações de soja, em reais, do período inicial para o final, é definido por:

$$
R_{t}-R_{0}=\left(R_{t}^{P}-R_{0}\right)+\left(R_{t}^{\lambda}-R_{t}^{P}\right)+\left(R_{t}-R_{t}^{\lambda}\right)
$$

em que $\mathrm{R}_{\mathrm{t}}-\mathrm{R}_{0}$ é a variação total na receita em reais; $\left(\mathrm{R}_{t}^{\mathrm{P}}-\mathrm{R}_{0}\right)$ mede a contribuição do preço internacional para a variação da receita; $\left(\mathrm{R}_{t}^{\lambda}-\mathrm{R}_{\mathrm{t}}^{\mathrm{P}}\right)$ mede a contribuição do efeito câmbio e $\left(\mathrm{R}_{t}-\mathrm{R}_{\mathrm{t}}^{\lambda}\right)$ afere a contribuição da variação no volume exportado, ou seja, o "efeito quantidade", 
Sonia Sueli Serafim de Souza, Janice Alves Lamera,

Sandra Cristina de Moura Bonjour \& Adriano Marcos Rodrigues Figueiredo

representando a variação da receita devido à variação do volume exportado.

$\mathrm{Na}$ expressão (8), é possível observar cada um dos três efeitos individualmente ou somados como a expressão apresenta, sendo, nesse caso, a taxa anual de crescimento da receita de exportação. Para descobrir a participação de cada um dos efeitos na variação total das receitas de exportação, multiplicam-se ambos os lados da expressão (8) por $1 /\left(\mathrm{R}_{\mathrm{t}}-\mathrm{R}_{0}\right)$; logo, tem-se:

$$
1=\frac{\left(\mathrm{R}_{t}^{\mathrm{P}}-\mathrm{R}_{0}\right)}{\left(\mathrm{R}_{\mathrm{t}}-\mathrm{R}_{0}\right)}+\frac{\left(\mathrm{R}_{t}^{\lambda}-\mathrm{R}_{\mathrm{t}}^{\mathrm{P}}\right)}{\left(\mathrm{R}_{\mathrm{t}}-\mathrm{R}_{0}\right)}+\frac{\left(\mathrm{R}_{t}-\mathrm{R}_{\mathrm{t}}^{\lambda}\right)}{\left(\mathrm{R}_{\mathrm{t}}-\mathrm{R}_{0}\right)}
$$

Pode-se ainda representar cada um dos efeitos estudados em percentual do efeito total, realizando a multiplicação dos dois lados da identidade (9) por $i=\left(\sqrt[t]{R_{t} / R_{0}}-1\right) .100, \quad \mathrm{e}, \quad \mathrm{com} \quad \mathrm{t}=1$, tem-se $i=\left[\left(R_{t} / R_{0}\right)-1\right] .100$, em que i representa a taxa média anual (em \%) de variação da receita das exportações, ou seja, o efeito total. Assim, os efeitos que atuam sobre a receita de exportação, em percentual, são dados por:

$$
i=\frac{\left(\mathrm{R}_{t}^{\mathrm{P}}-\mathrm{R}_{0}\right)}{\left(\mathrm{R}_{\mathrm{t}}-\mathrm{R}_{0}\right)} i+\frac{\left(\mathrm{R}_{t}^{\lambda}-\mathrm{R}_{\mathrm{t}}^{\mathrm{P}}\right)}{\left(\mathrm{R}_{\mathrm{t}}-\mathrm{R}_{0}\right)} i+\frac{\left(\mathrm{R}_{t}-\mathrm{R}_{\mathrm{t}}^{\lambda}\right)}{\left(\mathrm{R}_{\mathrm{t}}-\mathrm{R}_{0}\right)}
$$

em que os três termos à direita do sinal de igualdade representam os três efeitos, em percentual, na mesma seqüência da expressão (8). 


\subsection{Fonte dos Dados}

Os dados de quantidade exportada, preço e receita de exportação de soja em grão são da Secretaria do Comércio Exterior (MDIC, 2006); a taxa de câmbio nominal (R\$/US\$) foi obtida no Instituto de Pesquisa Econômica Aplicada (Ipeadata, 2006); o Índice Geral de Preços Disponibilidade Interna (IGP-DI), utilizado como Proxy para a inflação do Brasil, foi obtido na Fundação Getúlio Vargas (FGV-Dados, 2006); e, por fim, o Índice de Preços ao Consumidor (IPC) dos Estados Unidos foi obtido no Banco Central do Brasil (Banco Central Do Brasil, 2006).

O período estudado correspondeu aos anos de 1994 a 2005, razão pela qual todos os dados têm o ano de 2005 como base para deflacionamento.

A taxa de câmbio real foi obtida a partir de taxas médias anuais para o período de 1994 a 2005, deflacionadas pelo critério da paridade do poder de compra da moeda, conforme a expressão (11), considerando a inflação doméstica e a inflação internacional:

$$
\lambda=e \frac{P^{*}}{p}
$$

em que $\lambda$ é a taxa real de câmbio do Brasil (R\$/US\$, base 2005); $e$, a taxa nominal de câmbio do Brasil (R \$US\$); $\mathrm{P}^{*}$, a variação do índice de preços internacionais (IPC dos Estados Unidos, $2005=100$ ); e p, o índice de preços domésticos (IGP-DI, $2005=100)$.

\section{Resultados e Discussão}

Como se pode observar na Figura 3 (a), no período de 1994 a 2005 as receitas de exportação de soja em grão cresceram consideravelmente - mais especificamente, à taxa geométrica de crescimento de 22,06\% ao ano entre 1994 e 2005. Contudo, esse crescimento não foi contínuo e 
Sonia Sueli Serafim de Souza, Janice Alves Lamera,

Sandra Cristina de Moura Bonjour \& Adriano Marcos Rodrigues Figueiredo

ocorreu principalmente nos anos após a desvalorização da taxa de câmbio, no ano de 1999, demonstrando considerável expansão na quantidade exportada, apesar dos baixos preços no mercado internacional.

A evolução da taxa de câmbio real pode ser observada na Figura 3 (b), que teve seu pico no ano de 2003, ano em que o real se apresentou mais valorizado no período, com taxa geométrica de crescimento de $4,26 \%$ ao ano no período estudado.

No item (c) da Figura 3, pode-se observar que a quantidade exportada de soja tem crescido constantemente, sendo a taxa geométrica de crescimento de $18,29 \%$ ao ano para o período. O farelo e o óleo de soja também tiveram crescimento em sua quantidade exportada, embora mais modestamente que o crescimento da exportação do grão, e a produção nacional de soja praticamente dobrou no período.
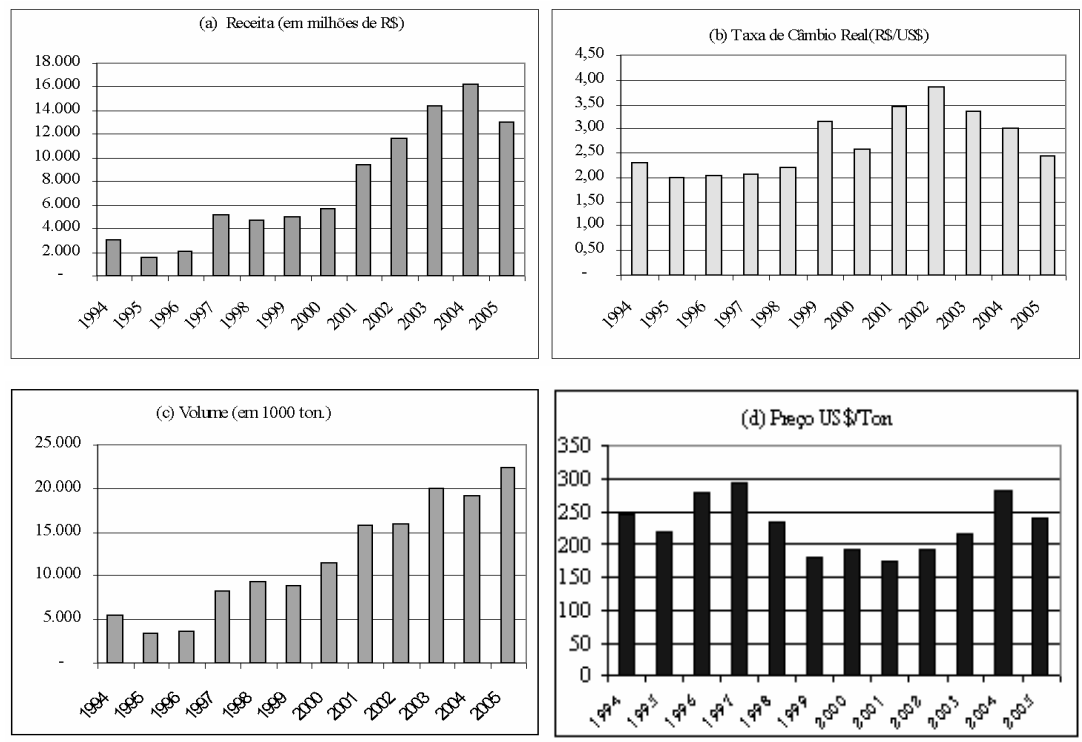

Figura 3 - Receita de exportação de soja, taxa de câmbio real, volume exportado e preço em dólares - 1994-2005.

Fonte: MDIC, FGV Dados e Banco Central do Brasil. 
A Figura 3 (d) mostra que o preço foi cíclico, provavelmente em virtude do aumento da produção mundial do produto, intercalado com quebras de safra, o que, como se sabe, influenciou decisivamente os preços internacionais. Para esta variável observou-se taxa geométrica de crescimento negativa de $1,03 \%$ ao ano entre 1994 e 2005, demonstrando que o efeito do aumento da quantidade produzida teve maior impacto que o efeito causado pelas quebras de safra.

$\mathrm{Na}$ Tabela 1 são apresentados os valores das variáveis do modelo — os mesmos da Figura 3; assim, o leitor atento pode observar os números das oscilações anteriormente comentadas.

Ao analisar o coeficiente de variação $(\mathrm{CV})$, pode-se observar que a quantidade exportada foi a variável que mais apresentou variação $(\mathrm{CV}=$ $54,53 \%$ ), o que reflete a expansão da cultura no Brasil, que até o ano 2000 permanecia abaixo da média do período e nos cinco anos seguintes praticamente dobrou. 
Sonia Sueli Serafim de Souza, Janice Alves Lamera,

Sandra Cristina de Moura Bonjour \& Adriano Marcos Rodrigues Figueiredo

Tabela 1 - Quantidade, preço e receita das exportações brasileiras de soja em grão e câmbio real — 1994 a $2005^{*}$

\begin{tabular}{ccccc}
\hline Ano & $\begin{array}{c}\text { Quantidade } \\
(1.000 \mathrm{t})\end{array}$ & $\begin{array}{c}\text { Preço } \\
(\mathrm{US} \$ \text { t })\end{array}$ & $\begin{array}{c}\text { Câmbio } \\
\text { Real }\end{array}$ & Receita (em reais) \\
\hline 1994 & 5.367 & 245 & 2,30 & $3.024 .972 .470,89$ \\
1995 & 3.493 & 220 & 2,01 & $1.544 .944 .117,36$ \\
1996 & 3.647 & 279 & 2,04 & $2.078 .075 .173,37$ \\
1997 & 8.340 & 294 & 2,08 & $5.096 .685 .972,23$ \\
1998 & 9.288 & 234 & 2,19 & $4.753 .760 .887,98$ \\
1999 & 8.917 & 179 & 3,15 & $5.032 .240 .717,98$ \\
2000 & 11.517 & 190 & 2,57 & $5.632 .565 .340,30$ \\
2001 & 15.676 & 174 & 3,45 & $9.396 .279 .893,44$ \\
2002 & 15.970 & 190 & 3,84 & $11.657 .646 .696,17$ \\
2003 & 19.890 & 216 & 3,35 & $14.406 .314 .094,36$ \\
2004 & 19.248 & 280 & 3,00 & $16.156 .198 .125,45$ \\
2005 & 22.435 & 238 & 2,43 & $12.997 .732 .182,24$ \\
\hline Média & 11.982 & 228,25 & 2,70 & $7.648 .117 .972,65$ \\
CV & 54,53 & 17,97 & 23,36 & 66,12 \\
\hline *
\end{tabular}

*em valores médios anuais.

Fonte: MDIC, FGV Dados e Banco Central do Brasil.

Diferentemente dos demais dados, a quantidade exportada de soja em grão apresentou crescimento quase que contínuo, com exceção do ano de 1999, refletindo a queda de preço em 2004, devido à valorização do câmbio. Já o preço internacional da commodity apresentou a menor oscilação entre as três variáveis, permanecendo entre os limites de US\$ 174 e US\$ 294 por tonelada — uma diferença de 69,9\%. Por esse intervalo de variação ser relativamente menor que o das demais variáveis, ocorreu nesse caso o menor coeficiente de variação $(17,97 \%)$. Em cinco anos, dos onze estudados, o preço esteve abaixo da média, sendo quatro depois da desvalorização do câmbio, que assegurou melhor condição na receita do produtor/exportador nesses anos.

A taxa de câmbio reflete claramente a política adotada nos primeiros anos do Plano Real, inicialmente valorizado, com forte desvalorização 
em 1999. Essa desvalorização é refletida na média do período, pois os anos em que a taxa de câmbio esteve acima da média condizem com a desvalorização do real. Seu coeficiente de variação reflete uma oscilação média comparativamente às demais variáveis, e o coeficiente de variação representa essa oscilação, com percentual de $23,36 \%$.

Na Tabela 2 são apresentados os resultados da decomposição dos três efeitos sobre a receita de exportação de soja em grão. O efeito total mostra que a receita de exportação somente apresentou declínio em três anos, com queda acentuada de 1994 para 1995 (-48,93\%), ocasionada pela situação adversa nas três variáveis que a determinam: o preço internacional declinou, o câmbio se valorizou e a quantidade exportada caiu mais acentuadamente, sendo a principal causadora da queda na receita. Uma segunda redução na receita comparativamente ao ano anterior foi em 1998, em que uma forte queda nos preços internacionais não pôde ser sustentada pela melhor posição do volume exportado e pela taxa de câmbio suavemente desvalorizada. O terceiro e último retrocesso na receita aconteceu em 2005, proporcionado pela valorização da taxa de câmbio e queda dos preços internacionais, uma vez que o crescimento da quantidade exportada não foi suficiente para sustentar a receita, que declinou em 19,55\% com relação ao ano anterior. 
Sonia Sueli Serafim de Souza, Janice Alves Lamera,

Sandra Cristina de Moura Bonjour \& Adriano Marcos Rodrigues Figueiredo

Tabela 2 - Decomposição da taxa anual de crescimento das receitas de exportação de soja em grão (em \%), de 1995 a 2005

Ano Efeito Preço Efeito Câmbio Efeito Quantidade Efeito Total

\begin{tabular}{lcccc}
\hline 1995 & $-10,20$ & $-11,32$ & $-27,40$ & $-48,92$ \\
1996 & 26,82 & 2,01 & 5,68 & 34,51 \\
1997 & 5,38 & 1,87 & 138,01 & 145,26 \\
1998 & $-20,41$ & 4,16 & 9,52 & $-6,73$ \\
1999 & $-23,50$ & 33,77 & $-4,40$ & 5,87 \\
2000 & 6,15 & $-19,48$ & 25,27 & 11,94 \\
2001 & $-8,42$ & 30,98 & 44,26 & 66,82 \\
2002 & 9,20 & 12,59 & 2,28 & 24,07 \\
2003 & 13,68 & $-14,46$ & 24,36 & 23,58 \\
2004 & 29,63 & $-13,74$ & $-3,74$ & 12,15 \\
2005 & $-15,00$ & $-15,98$ & 11,43 & $-19,55$ \\
\hline
\end{tabular}

Fonte: Dados da pesquisa.

Não houve predomínio de nenhum efeito por todo o período analisado, conforme a Figura 4; como foram anos de grandes variações na taxa de câmbio, na quantidade exportada e nos preços, houve variação de efeito dominante ano a ano.

O efeito preço, ou seja, as variações do preço internacional da soja sobre a receita de exportação, predominou nos anos de 1996, 1998 e 2004. No ano de 1996, um plausível crescimento nas receitas foi proporcionado pela melhoria nas três variáveis; entretanto, nota-se apenas uma discreta melhora na taxa de câmbio e na quantidade exportada, predominando o efeito preço, com o preço da tonelada de soja em grão saltando de US\$ 220 para US\$279. Em 1998, o preço médio internacional da tonelada de soja esteve US\$ 60 abaixo do preço de 1997, tendo sido o maior responsável pela redução de $6,73 \%$ na receita. No entanto, essa retração em 1998 deveria ser de $-20,41 \%$ se dependesse unicamente do preço; ela foi amenizada pelos efeitos positivos do câmbio $(4,16 \%)$ e da quantidade exportada $(9,52 \%)$. 


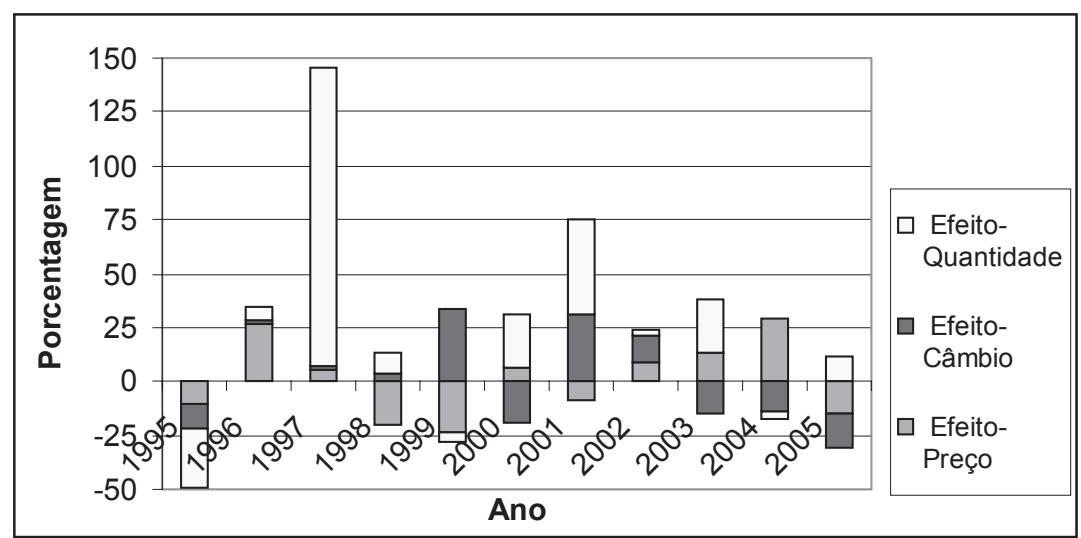

Figura 4 - Decomposição da taxa anual de crescimento das receitas de exportação de soja em grão (em \%) - 1995 a 2005.

Fonte: Dados da pesquisa - Tabela 2.

Em 2004 ocorreu o inverso de 1998, pois foi o efeito positivo do preço que assegurou uma receita $12,15 \%$ maior do que a do ano anterior aos exportadores. A influência do câmbio sobre as receitas de exportação predominou sobre os demais efeitos nos anos de 1999, 2002 e 2005. Embora não predominante no restante do período, o câmbio também repercutiu negativamente na receita de exportação por vários anos.

Em janeiro de 1999, a política de preservação do câmbio valorizado chegou ao seu fim, principalmente por causa da crise russa, que provocou a aceleração na perda de reservas internacionais. Como a política se tornou insustentável, os responsáveis pela política macroeconômica permitiram a livre flutuação do câmbio brasileiro. Isso repercutiu nas receitas de exportações, que poderiam crescer em até $33,77 \%$, caso não houvesse variações nos preços e na quantidade exportada com relação a 1998. Contudo, o fato é que em 1999 o preço médio anual da tonelada de soja no mercado internacional foi de US\$174, bem abaixo dos US\$ 234 do ano anterior, e a quantidade exportada também declinou. O resultado foi uma receita de exportação de apenas 5,86\% superior à do ano anterior, apesar do bom êxito do efeito câmbio. 
Sonia Sueli Serafim de Souza, Janice Alves Lamera,

Sandra Cristina de Moura Bonjour \& Adriano Marcos Rodrigues Figueiredo

Observa-se que a taxa de câmbio é uma variável-chave para a agricultura de exportação, tendo considerável efeito sobre a competitividade dos produtos brasileiros no exterior. O efeito da taxa de câmbio sobre o mercado da soja foi evidente, em especial em 1995 e 2000, mostrando correlação direta entre a taxa de câmbio e a receita das exportações de soja em grão.

No ano de 2002, a receita cresceu $24,07 \%$ em relação ao ano anterior, decorrente do desempenho positivo de todas as variáveis, dentre as quais a taxa de câmbio foi a que mais contribuiu. Em 2005, as receitas das exportações decresceram 19,55\% em relação a 2004; os efeitos preço e câmbio foram os grandes responsáveis, apesar de ligeira superioridade deste último. Em virtude da grande quantidade produzida e destinada ao exterior, os produtores não lograram êxito, tendo início nesse ano uma crise no setor, que ainda persiste.

Sabe-se que a quantidade ofertada é largamente influenciada pelo preço e pela taxa de câmbio; logo, esse efeito foi o que predominou na maioria dos anos, mais precisamente em 1995, 1997, 2000, 2001 e 2003.

Em 1995, a redução da quantidade exportada parece estar totalmente ligada à situação do preço e do câmbio, ou seja, houve valorização do câmbio e queda dos preços internacionais da soja. Em 1997, um grande aumento na quantidade exportada de soja em grão parece não ter sido totalmente influenciado pela situação do câmbio e do preço, que apresentaram apenas discreta melhora. Logo, isso pode ser decorrente de uma queda na demanda interna, uma vez que o aumento da quantidade produzida sozinha não foi suficiente para explicar esse notável crescimento na quantidade exportada. O aumento de $145,26 \%$ na receita de exportação com relação a 1996 deve-se quase que integralmente $(138,01 \%)$ ao aumento da quantidade exportada, que saltou de 3.647 para 8.340 milhões de toneladas.

Em 2000, a taxa de câmbio se valorizou com relação ao ano anterior, passando de 3,15 para 2,57 R\$ por US\$, de 1999 para 2000, mas a pronunciada queda na receita foi assegurada por notável elevação na 
quantidade exportada, que, no caso das demais variáveis constantes, geraria $25,27 \%$ de aumento na receita do exportador. Portanto, diante do negativo desempenho do efeito câmbio, foi o aumento na quantidade que assegurou crescimento das receitas das exportações de 11,93\%, comparativamente a 1999 .

Assim como em 2000, nos anos de 2001 e 2003, a elevação da quantidade exportada foi decisória para o bom êxito da receita de exportação; em 2001, auxiliadas pelo também bom desempenho do efeito câmbio, as exportações proporcionaram renda elevada ao produtor/exportador.

Como demonstrado nos dados, desde o pico máximo do câmbio real, em 2002, o real tem se valorizado diante do dólar, o que tem prejudicado acentuadamente as receitas dos exportadores de commodities, como os sojicultores brasileiros. Observe que, devido a elevações do volume exportado e ao preço internacional, a receita ainda cresceu em 2003 e 2004; contudo, em 2005 uma queda no preço internacional e uma nova valorização do câmbio foram decisivas para derrubar a receita de exportação da soja em 19,55\%, com relação a 2004. Desde o segundo semestre de 2004, tem-se observado a queda dos preços internacionais da soja, o que tem atingido desfavoravelmente o setor até os dias atuais.

Em geral, variações bruscas dos preços agrícolas internacionais, como a ocorrida em 2004, se dão após variações na produção mundial, uma vez que a produção de soja é muito concentrada em poucos países, e uma irregularidade climática em um país produtor provoca grandes variações na oferta mundial.

Brandão et al. (2005) apontam também a baixa elasticidade-preço da oferta agregada e individual para explicar os ciclos no mercado internacional de grãos, visto que uma queda de preço não leva à redução da oferta nos EUA, Brasil e Argentina. Assim, a fase de baixos preços só pode ser revertida com quebra de safra num dos grandes produtores mundiais. 
Sonia Sueli Serafim de Souza, Janice Alves Lamera,

Sandra Cristina de Moura Bonjour \& Adriano Marcos Rodrigues Figueiredo

Diante da recuperação da safra norte-americana e da valorização do câmbio, os agricultores brasileiros perdem competitividade, pois, diferentemente dos norte-americanos, não recebem grandes subsídios do governo, não têm um mercado de crédito bem-desenvolvido, operam numa economia com altos juros, elevados custos de frete até os distantes portos, entre outros fatores que lhes têm tirado a competitividade.

\section{Conclusões}

Analisando os resultados obtidos, pode-se verificar que o efeito quantidade, ou seja, a quantidade exportada de soja em grão, foi a variável mais relevante para explicar o crescimento das receitas brasileiras de exportação da referida commodity. Esse notável crescimento pode ter sido em função de políticas adotadas para incentivar as exportações, como, por exemplo, a Lei Kandir, que beneficia as exportações do produto in natura em detrimento das exportações dos produtos processados.

O grande aumento observado na produção do Brasil tem sido para atender principalmente à demanda externa. Essa conclusão pode ser reforçada com números, pois, enquanto em 1994 o Brasil exportava 22\% de sua produção de soja em grão, em 2005 foram exportados 44\%; a quantidade excedente da produção sobre a exportação, destinada à produção de óleo e farelo para exportação e para a demanda interna, cresceu apenas $50 \%$, comparativamente aos $318 \%$ da quantidade exportada anteriormente mencionada.

O efeito preço foi responsável por acentuadas variações na receita de exportação, parecendo ter reagido a aumentos no estoque mundial e a quebras de safra, em harmonia, portanto, com os pressupostos da teoria econômica. Assim como os dois outros efeitos, o efeito câmbio também foi determinante para o bom desempenho das receitas de exportação de soja. As duas diferentes políticas cambiais adotadas no período são claramente observadas ao analisar os dados de quantidade e receita de exportação; apesar da boa fase dos preços internacionais entre 1995 e 
1998, a política cambial inibiu a exportação da commodity.

A participação crescente do Brasil nesse mercado exportador deveu-se ao aumento da competitividade da soja brasileira, em virtude da isenção do ICMS sobre o produto; da desvalorização do câmbio ocorrida em janeiro de 1999, que alterou os termos de troca em favor dos produtores brasileiros; e do aumento da produtividade, que contribuiu para a redução dos custos de produção. Entretanto, a queda dos preços internacionais, de 1998 a 2002, anulou grande parte dos benefícios da desvalorização cambial.

Num cenário de crise, como o que estão vivendo os produtores brasileiros de soja, mesmo sabendo da extrema importância da taxa de câmbio para a exportação, esta não deve ser utilizada para elevar a renda de um setor da economia em caso de crise deste setor, pois isso geraria uma artificialidade que distorceria significativamente os preços relativos, uma vez que não há como definir um câmbio para cada setor.

Assim, o efeito câmbio não é o único responsável pela situação desfavorável. Há uma soma de efeitos, como problemas climáticos e de pragas, que influenciaram os custos de produção, tornando o setor menos competitivo no mercado internacional.

\section{Referências}

BANCO CENTRAL DO BRASIL. Séries Relacionadas (IPC-EUA), Brasília, 1994 a 2005. Disponível em:<http://www.bcb.gov.br.> Acesso em: 15 jun. 2006.

BRANDÃO, A. S. P.; REZENDE, G. C. de; MARQUES, R. W. da C. Crescimento agrícola no Brasil, no período 1999-2004: explosão da soja e da pecuária bovina e seu impacto sobre o meio ambiente. Rio de Janeiro: IPEA, jul. 2005. (Texto para discussão n. 1103). 
Sonia Sueli Serafim de Souza, Janice Alves Lamera,

Sandra Cristina de Moura Bonjour \& Adriano Marcos Rodrigues Figueiredo

CANUTO, O.; XAVIER, C. L. Padrões de especialização e competitividade no comércio exterior brasileiro: uma análise estrutural-diferencial. Campinas: IE/UNICAMP, set. 1999. (Texto para discussão n. 86).

CENTRO DE ESTUDOS AVANÇADOS EM ECONOMIA APLICADA - CEPEA. PIB do Agronegócio, Piracicaba, 2006. Disponível em: $<$ http://www.cepea.esalq.usp.br $>$ Acesso em: 30 maio 2006.

CONFEDERAÇÃO DA AGRICULTURA E PECUÁRIA DO BRASIL - CNA. Indicadores Rurais, Brasília, 2006. Disponível em:< http:// www.cna.org.br > Acesso em: 30 mai. 2006.

CARTA do IBRE. Conjuntura Econômica. fevereiro de 2006. Disponível em: <http://www.cepea.esalq.usp.br.> Acesso em: 10 mar. 2006.

CURTIS, W. C. Shift-share analysis as technique in rural development research. American Journal of Agricultural Economics, Ithaca, v. 54, n. 2, p. 267-270, 1972.

FILGUEIRAS, G. C.; HOMMA, A. K. O.; SANTANA, A. C.; IGREJA, A. C. M.; HERREROS, M. M. A. G. Fontes de crescimento do setor agrícola no estado do Pará: avaliação pelo método shift-share. In: CONGRESSO NACIONAL DE ECONOMIA E SOCIOLOGIA RURAL, 41., 2003, Juiz de Fora. Anais... Juiz de Fora: Embrapa Gado de Leite, 2003. 1 CD-ROM.

FUNDAÇÃO GETÚLIO VARGAS. FGVDADOS (IGP-DI). Índices Gerais de Preços. Rio de Janeiro, 1994 a 2005. Disponível em: <http:/ /www.fgvdados.br/dsp_frs_pai_ferramentas.asp> Acesso em: 25 jun. 2006. 
IGREJA, A. C. M.; BLISKA, F. M. M.; FILGUEIRAS, G. C.; MARTINS, S. S.; TIRADO, G. Fator locacional na produção brasileira de carne bovina: uma análise comparada utilizando estatísticas de produção inspecionada versus produção total. In: CONGRESSO NACIONAL DE ECONOMIA E SOCIOLOGIA RURAL, 43., 2005, Ribeirão Preto. Anais... Ribeirão Preto: ESALQ-USP, 2005. 1 CD-ROM.

IGREJA, A. C. M.; ROCHA, M. B.; TSUNECHIRO, A. Fatores de ajuste da oferta de milho safrinha em relação à oferta total de milho, de acordo com as fontes de crescimento da produção. In: CONGRESSO NACIONAL DE ECONOMIA E SOCIOLOGIA RURAL, 43., 2005, Ribeirão Preto. Anais... Ribeirão Preto: ESALQ-USP, 2005. 1 CD-ROM.

INSTITUTO BRASILEIRO DE GEOGRAFIA E ESTATÍSTICA. Pesquisa Agrícola Municipal. Rio de Janeiro, 1994 a 2005. Disponível em: $<$ http://www.sidra.ibge.gov.br/bda/acervo $>$ Acesso em: 15 jun. 2006.

INSTITUTO DE PESQUISA ECONÔMICA APLICADA (IPEADATA). Dados macroeconômicos. Brasília, 1994 a 2005. Disponível em: <www.ipeadata.gov.br>Acesso em: 5 jul. 2006.

MDIC. Ministério do Desenvolvimento Indústria e Comércio Exterior. Brasília. Exportações, 1994 a 2005. Disponível em: <http:// www.aliceweb. desenvolvimento.gov.br/alice.asp.> Acesso em: 17 mai. 2006.

REIS, S. M.; CAMPOS, R. T. Efeitos da taxa de câmbio sobre os preços do cacau. In: CONGRESSO NACIONAL DE ECONOMIA E SOCIOLOGIA RURAL, 36., 1998, Poços de Caldas. Anais... Poços de Caldas: SOBER. 1998. 1 CD-ROM

ROMÃO, M. C.; BEZERRA, J. F.; VERGOLINO, J. R.. Metodologia para estimação de impactos da irrigação sobre o emprego urbano. Revista de Economia e Sociologia Rural, Brasília, n. 3, 1989. 
Sonia Sueli Serafim de Souza, Janice Alves Lamera,

Sandra Cristina de Moura Bonjour \& Adriano Marcos Rodrigues Figueiredo

SANTOS, S. A.; SILVA, C. R. L. Política agrícola e eficiência econômica: o caso da agricultura paulista. In: CONGRESSO NACIONAL DE ECONOMIA E SOCIOLOGIA RURAL, 39., 2001, Recife. Anais... Recife: UFPE, 2001. 1 CD-ROM.

SHIKIDA, P. F. A.; ALVES, L. R. A. Panorama estrutural, dinâmica de crescimento e estratégias tecnológicas da agroindústria canavieira paranaense. Revista Nova Economia, Belo Horizonte, v. 11, n. 2, dez. 2001.

SILVA, C. R. L. Uma tentativa de avaliação das possibilidades de geração de emprego da agricultura brasileira. In: CONGRESSO NACIONAL DE ECONOMIA E SOCIOLOGIA RURAL, 37., 1999, Foz do Iguaçu. Anais... Foz do Iguaçu: SOBER, 1999. 1 CD-ROM

SILVA, C. R. L.; CARVALHO, M. A. Taxa de câmbio e preços de commodities agrícolas. Revista Informações Econômicas, São Paulo, v. 25, n. 5, p. 23-35, maio 1995.

SILVA, S. P.; FARIA, R. A.; GOMES, M. F. M. Mudança da composição agrícola do sul goiano, no período de 1985 a 1995. In: CONGRESSO NACIONAL DE ECONOMIA E SOCIOLOGIA RURAL, 37., 1999, Foz do Iguaçu. Anais... Foz do Iguaçu: SOBER, 1999. 1 CD-ROM.

SOUZA, P. M.; LIMA, J. E.; PONCIANO, N. J. Mudanças na composição da produção agrícola nos estados das regiões Norte e Nordeste, 1975-1995. RECITEC - Revista Eletrônica da Fundação Joaquim Nabuco, Recife, v. 6, n.1, p. 93-117, 2002. Disponível em: $<$ http://www.fundaj.gov.br.> Acesso em: 15 jun. 2006. 
Abstract - This paper analyzes exchange rate, export quantity and foreign soybean price in soybean export revenues between 1994 and 2005. We used the shift-share method which allowed the isolation of effects for each variable. The results evidenced that even with adverse exchange rates and foreign prices the quantities exported were increasing in almost all the period. The two main trade policies in act by the Brazilian Government, since the beginning of the Real Plan in 1994, were clearly decisive for the increase in soybean export revenues and exported quantities.

Key-words: Exchange rate, export revenues, soybean. 